\title{
ANALYSIS OF RUNWAY DEFLECTOMETER CAMPAIGN FOR IMPLEMENTATION ON AIRPORT PAVEMENT MANAGEMENT SYSTEM
}

Franco Pigozzi, PhD student, Department of Civil, Environmental and Architectural Engineering, University of Cagliari, Italy. Email: franco.pigozzi@unica.it

Silvia Portas, Prof., Department of Civil, Environmental and Architectural Engineering, University of Cagliari, Italy.Email: sportas@unica.it

Francesca Maltinti, Prof., Department of Civil, Environmental and Architectural Engineering, University of Cagliari, Italy.Email: maltinti@unica.it

Mauro Coni, Prof., Department of Civil, Environmental and Architectural Engineering, University of Cagliari, Italy. Email: mconi@unica.it

doi: 10.2478/ijpeat-2013-0009

\begin{abstract}
The load-carrying capacity, is one of the indicators used to assess airfield pavement conditions. It could be estimated by evaluating the response of stationary dynamic loads, using a deflectometric device that simulates the stress inducted by an aircraft moving at moderate speed. This device is widely used because tests are nondestructive and rapid to execute and can be conducted for cyclic investigations, providing valuable support to maintenance and rehabilitation $(\mathrm{M} \& \mathrm{R})$ decision makers through pavement management system (PMS). Pavement response is evaluated as a function of the deflection basin induced by the deflectometric device. It is well known that deflectometric measurements are influenced by external parameters such as weather conditions, especially temperature of upper layers or the percentage of water contained on unbounded layers. In this study the deflections basin response obtained for different load and weather conditions has been analyzed through the application of benchmarking values for immediately structural assessments. Tests were performed using the Heavy Weight Deflectometer (HWD) on 9 points along five longitudinal alignments from the centerline, $0.00 \mathrm{~m}, \pm 3.00 \mathrm{~m}$, and $\pm 5.20 \mathrm{~m}$. The benchmarking methodology was used to evaluate and compare runway pavement performance under different weather conditions and testing loads. The applied benchmarking methodology resulted an easy and rapid assessment tool of pavement conditions at network-level.
\end{abstract}

\section{Introduction}

The increasing demand for air transportation, also for small and medium airports, induces greater attention on the overall and continuous assessment of runway and taxiways pavement conditions. However, this need often contrasts with limited available budget. The development of new optimized tools, easy to apply and inexpensive, becomes a key objective of airport operators continuously faced with reliable evaluation of paved areas structural condition subjected to aircraft loads.

The reported study focused the attention on the possible use of old gathered data, and often collected without comparable conditions, to evaluate structural conditions of 
airport pavements for implementation on Airport Pavement Management System (APMS) in order to select the appropriate Maintenance and Rehabilitation (M\&R) actions.

A non-destructive and rapid to execute test widely used to simulate actions inducted by maneuvering aircrafts is conducted with deflectometric devices. These devices apply a stationary dynamic load to measure induced deflection basin in the tested pavement then back-calculation analysis could be used normally assuming multilayered elastic theory (Horak, 2009). The deflection of a pavement represents an overall response of the system pavement layer to an applied load. Deflection testing is currently the most widely used method for non-destructive evaluation of the structural capacity of a pavement. Pavement deflection measurements are important inputs to many pavement condition assessment tools, including structural capacity indicator tools and tools to calculate the remaining service life of pavements (Gadafa, et al., 2010). The basin shape traced with load allows preliminary considerations about loadcarrying capacity since it is related to structural pavement characteristics such as strength, layers thickness, subbase and subgrade mechanical properties.

Since layers moduli are influenced by temperature, especially on upper layers, and by percentage of water contained on lower unbound layers, seasonal changes may affect the deflectometric measurements inducing highest or lower deflections in the worst or best conditions, respectively. In addition, device parameter can affect deflection bowl depending on stress applied. Since the 1980s, significant improvement of nondestructive deflection measuring devices resulted in the ability to measure the whole deflection bowl accurately. It also enabled an appreciation of the value of the whole deflection bowl in structural analysis of road and airport pavements (Horak, 2009). Data gathered is used to back-calculation analysis process currently implemented on different software to estimate layer's moduli. However, this process can have some inaccuracies due to variance in assumption and modelling approaches. Worldwide development of back-calculation analysis procedures and associated software has happened over the past 10 to 15 years, but has run into various problems of credibility due to the uncertainties regarding material characterization, uniqueness of measuring equipment, personal interpretations, confusion of dynamic and static response and basic material variability (Ullidtz, et al., 2000). Also, they generally provide more detail than necessary for decision trees, making them less attractive and less cost effective for network-level applications. As a result, using pavement deflection testing for network-level analysis has been limited, even within agencies that extensively use a Falling Weight Deflectometer (FWD) for project-level analysis. However, some of these project-level techniques can be adapted to assist with network-level PMS applications. The key is to improve each technique in such a way that a simple parameter (or set of parameters) can be computed to describe the overall structural capacity of a uniform pavement section (Carvalho, et al., 2012).

In the last years, attention has been focused on deflection bowl investigation in order to obtain pavement evaluation without back-calculation analysis process and estimating relative damage (Donovan \& Tutumluer, 2009). It has been shown that deflection bowl parameters can be used in a benchmarking procedure to help identify weaker areas in pavements over length and width as well as in-depth of the pavement structure (identify structurally weak layers) to help optimize further detailed investigations (Horak, 2009). This benchmarking methodology with the associated 
condition ratings helps to accurately identify uniform sections and pinpoint the cause of structural distress, often seen only as various forms of surface distress, and helps to explain the mechanism of deterioration (Horak, 2007). Correlations between a number of deflection bowl parameters and mechanistically determined structural evaluations of a number of pavement types offer the possibility to use these parameters in a semiME fashion to analyze pavements. The parameters can also be used in a complementary fashion with visual surveys and other assessment methodologies to describe pavement structural layers as sound, warning or severe in respect of their structural capacities and behavior states (Horak, 2008). It has been argued that at a network level the maximum surface deflection under the load, obtained from structural capacity testing is probably all that is required to assess the structural capacity of a pavement (Haas, 1995). The maximum surface deflection under a standardized load will enable an ability to compare the structural condition of sections within the network. Without relating the peak deflection to expected traffic loadings, the use of peak deflection as an integral tool in the treatment selection process will be limited (Paine, 1998).

In order to develop a benchmarking methodology for assessment of deflectometer campaign results, the results obtained from deflectometric tests, executed in different climatic conditions and with different applied loads, have been analyzed. The benchmarking methodology has been focused to evaluate structural behavior of runway and taxiway pavement at network-level for pavement management. This part of the research the attention has been focus just on the peak deflection aiming to set an easy and rapid method that allows immediately assessments of the airport pavements. The analyzed deflection bowls were conducted at Olbia Airport. The deflection bowls were measured in different seasons and at various load levels, along two test sections of the runway, respectively $500 \mathrm{~m}$ and $900 \mathrm{~m}$ long, on three alignments at $0.00 \mathrm{~m}, \pm 3.00 \mathrm{~m}$, and $\pm 5.20 \mathrm{~m}$, for a total of 80 points surveyed

\section{Research Objective and Scope}

The aim of this work is to establish a simplified technique to assess structural conditions of airport pavements at network level for pavement management implementation. The network level studies aim at providing the proper decision level with information needed for budgeting, planning, programming and prioritization (COST 336, 1998). The scope was to investigate possible relationship between deflection bowls measured in different load and weather condition, in order to implement available deflection data on an airport pavement management system (APMS).

\section{Deflectometric Device and Factors Affecting Deflection Values}

The measured deflection bowl by applying an impulse load represents the overall response of pavement layers. The shape of basin and others information, i.e. maximum deflection or slope, may be used to assess quickly and easily the pavement bearing capacity. Higher deflections are often related to weaker pavement but the study of the exact shape can provide information about the strength of individual layers. Although maximum deflection based design procedures do provide a relatively sound basis for analysis, they are not without their limitations. Maximum deflection describes how the overall pavement system behaves under a load, but not necessarily, 
how the individual layers are going to resist fatigue or permanent deformation (Shahin, 2005). A parameter that affects the deflection basins is the magnitude of loads applied, as shown in Figure 1.

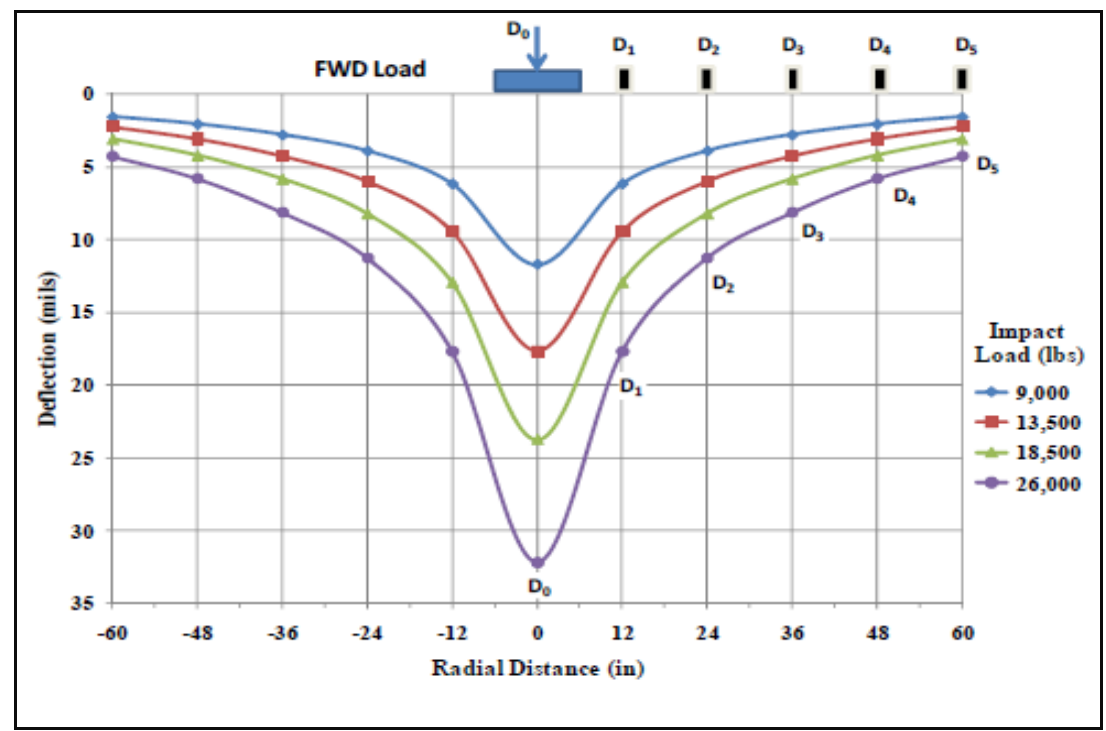

Figure 1. FWD basins for different applied load (Donovan \& Tutumluer, 2009)

Although load level can range from $7 \mathrm{kN}$ up to $240 \mathrm{kN}$, it is acknowledged that light loads do not stress sufficiently lower layers as subgrade and subbase, especially on paved areas subjected to aircraft stress, where evaluations conducted with inappropriate loads could be very misleading. During the analysis of deflection data, engineers often assume that all layers in the structure respond in a linear elastic mode. For most pavement structures and testing conditions, traditional paving materials will behave in a linear elastic manner within the load range that the tests are conducted. Generally, the impulse load should range between $90 \mathrm{kN}$ and $240 \mathrm{kN}$ on pavements serving commercial air carrier aircraft, provided the maximum reliable displacement sensor is not exceeded (FAA AC 150/5370-11B, 2011). It is recommended that the testing load should not be less than half the design load, obtained by airport traffic analysis and related previsions. The design load can be established prior test execution analyzing the historic traffic data of the inspected site and evaluating future previsions about the Aircraft Design Group (ADG) not only evaluating the most frequent but considering also aircraft categories with high loads.

The loading mode must be accurately established due to differences between the real deflection bowl due to a moving aircraft and the deflection measured by HWD. When a vehicle travels a pavement, there is always a deflection bowl around the wheel. The deflection bowl caused by HWD is different. It takes some time for the deflection to travel from the plate outward. The HWD measures the peak deflection of each geophone thus this data are used to construct the basin even though they did not occur at the same time. This error could be minimized by increasing the rise time. By using a sufficiently long rise time, the time lag between sensor peak deflection is minimized. The effect of the load pulse shape and rise time cannot be overlooked because it can affect deflection peak values by as much as $10 \%$ to $20 \%$ (Shahin, 2005). Another factor that must be closely monitored during test execution is the pavement temperature. That can seriously affect the strength of asphalt concrete layers due to the strictly relationship between temperature and asphalt modulus. At 
lower temperatures stiffness of AC layers is higher than measured at higher temperatures, consequently, deflection magnitude depends on test conditions, as illustrated on Figure 2. This material behavior has to be considered on post analysis for accurate deductions.

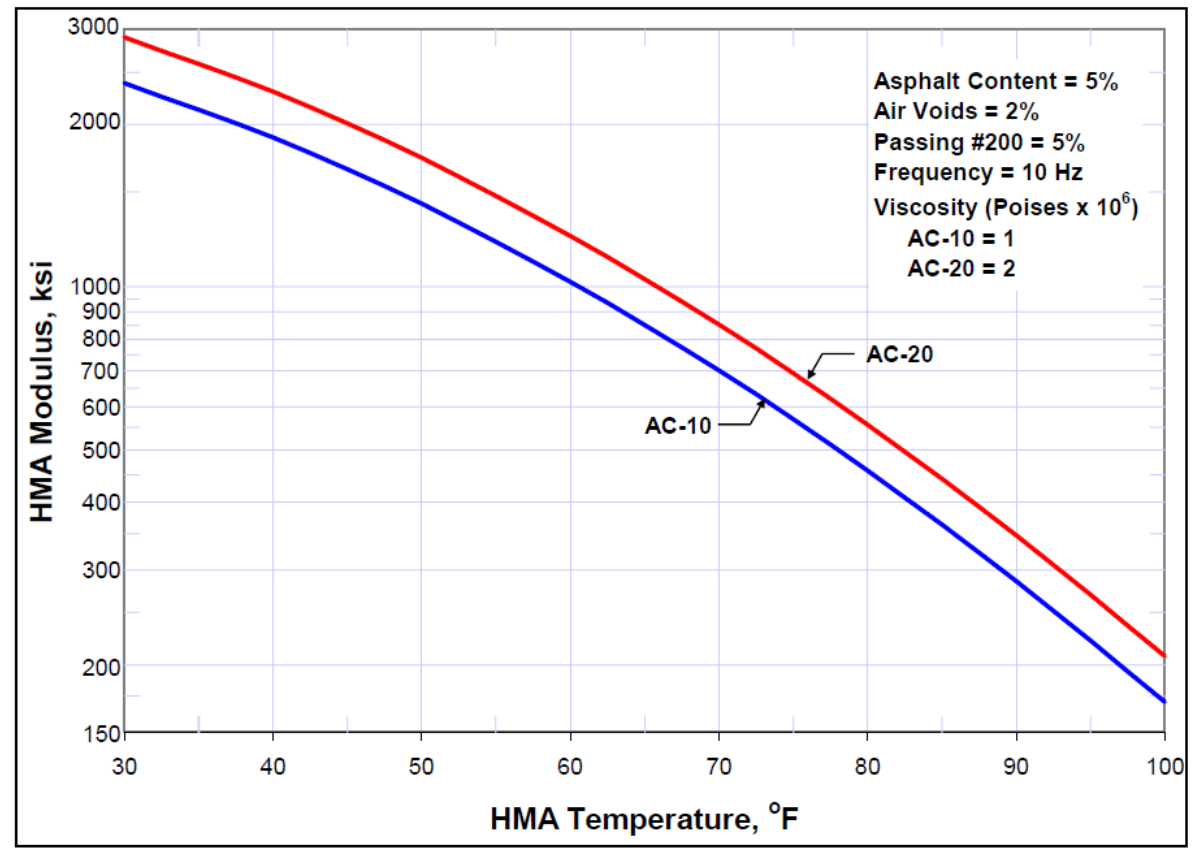

Figure 2. Typical AC Modulus-Temperature Relationship (Thompson \& Cation, 1986).

Also testing season is important in analyzing deflections. Significant seasonal variations usually affect pavement strength determined through FWD/HWD deflections. Such deflections might misinterpret the pavement's true condition (Peddibhotla, et al., 2011). In freeze-thaw areas, it is not recommended to conduct test on frost seasons. However the site investigate is not subjected to freeze-thaw cycles, then limitations on this aspect were not considered. In areas that do not experience freeze-thaw the deflections trend can be related to a sine curve, with the peak deflection occurring either in the spring when significant free moisture exists or in the hot summer in relatively dry area. In the case of flexible pavement, it is generally assumed that the stiffness of asphaltic materials vary with temperature, while unbound materials such as granular base and subgrades vary with moisture contents (Briggs \& Lukanen, 2000). Each agency must determine during what season the peak deflections are at a maximum. It is desirable that the deflection testing be conducted at this crucial season though for network-level deflection testing on completely thawed areas no limit on season execution are recommended (Carvalho, et al., 2012). If it is not possible, an adjustment factor should be applied to relate the measured deflection to the deflection that would be obtained during the critical season. This adjustment factor must account for both temperature and moisture variations (Shahin, 2005).

The increasing demand for air transportation implies the presence of larger and heavier airplanes with the need of assessing runway and taxiway pavement conditions using HWD higher loads. However, this need often contrasts with limited available budget, thus old gathered data, collected for lower loads and under various weather 
conditions, has to be used to predict remaining life of airport pavements for implementation on APMS in order to select the appropriate M\&R actions.

Tests conducted at Olbia "Costa Smeralda" Airport

The study was conducted using the data provided by "Costa Smeralda" Airport. It is a regional airport located on the northeastern coast of Sardinia Island, a region with mild climate all year around. It is a small airport with high seasonality, with approximately 30,000 annual aircrafts movements, with a peak on summer time as noticeable on Figure. 3, and a prevalence of tourist traffic.

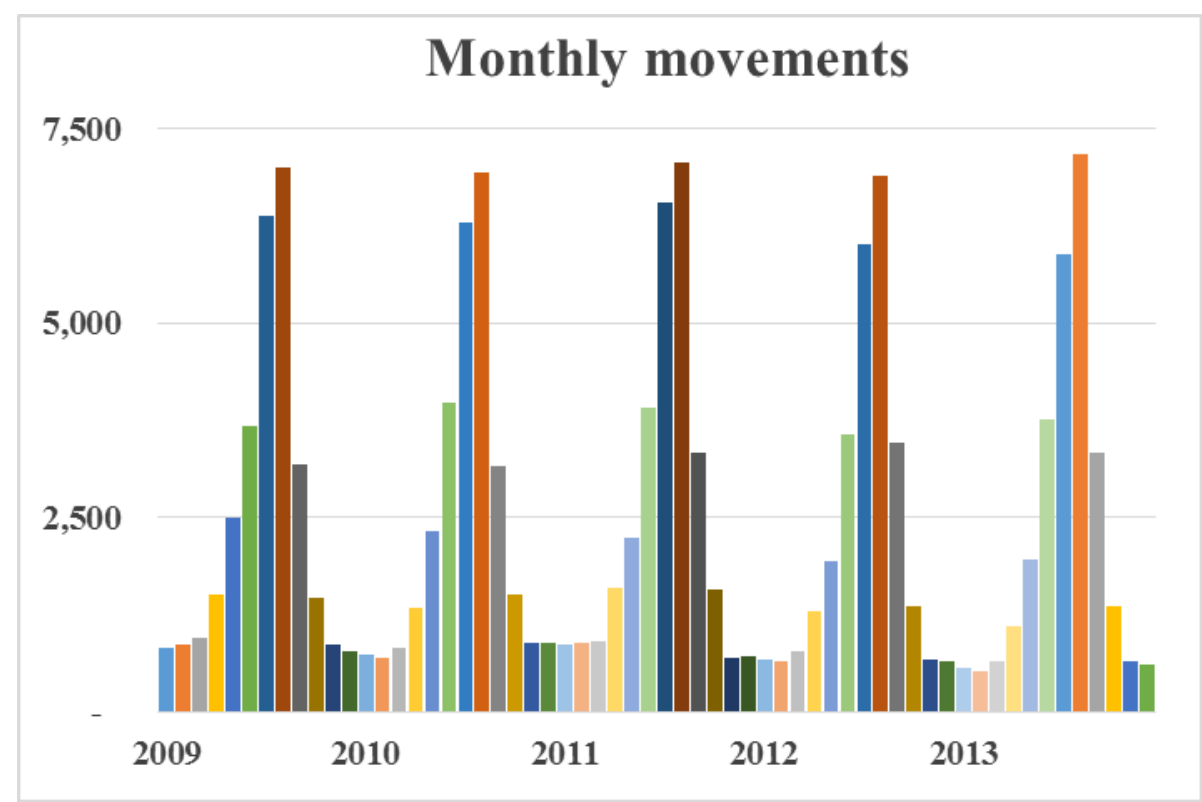

Figure. 3 Aircraft traffic distribution per months

The 70 percent of total year traffic is always distributed between June and September, while the remaining 30 percent is distributed throughout the rest of the year. This is a rather peculiar case in Italy because the airport management company is held by a commercial airline and here are also located the operational headquarters of an aircraft's maintenance company. The research was conducted on the runway that has a total length of 2,445 meters, of which 2,150 meters are in standard flexible pavement with bituminous stabilized base, while the remaining part, located on each threshold, is semi-rigid paved, as shown on Figure 4. 


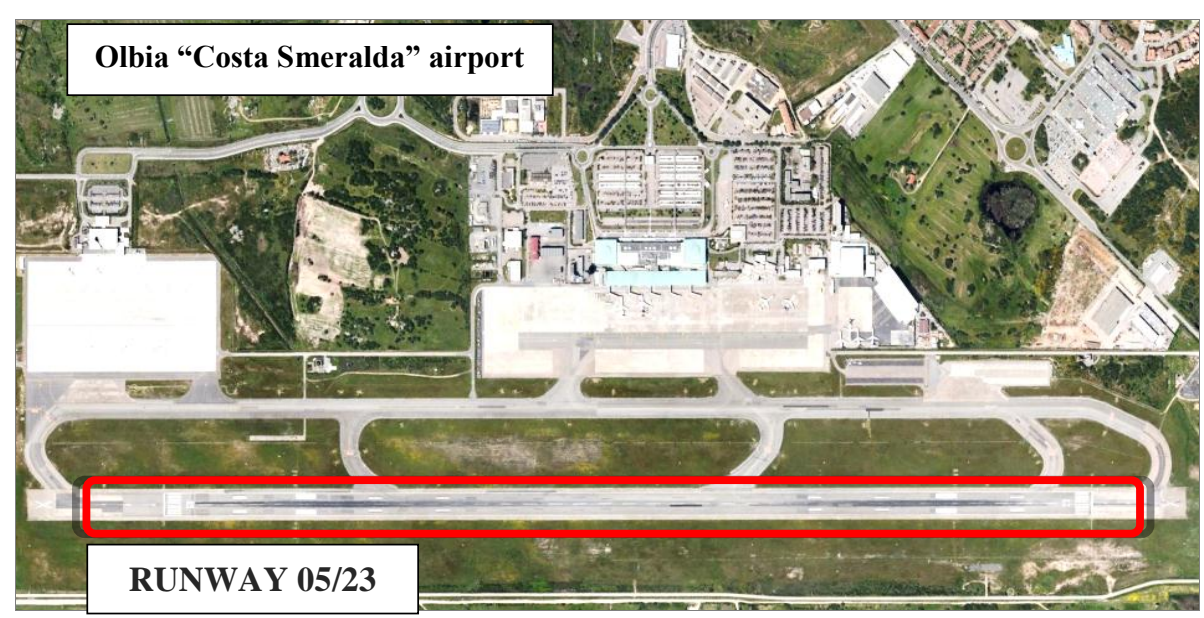

Figure 4. Olbia "Costa Smeralda" Airport layout

In the April 2013, an intensive HWD campaign was conducted interesting the whole maneuvering area, using the device shown in Figure 5. These tests are part of a wider survey program conducted by the airport management company aimed to acquire the mechanical conditions of runway, taxiways and aprons pavements. The thickness of pavement layers was determined with material sampling and using Ground Penetration Radar (GPR).

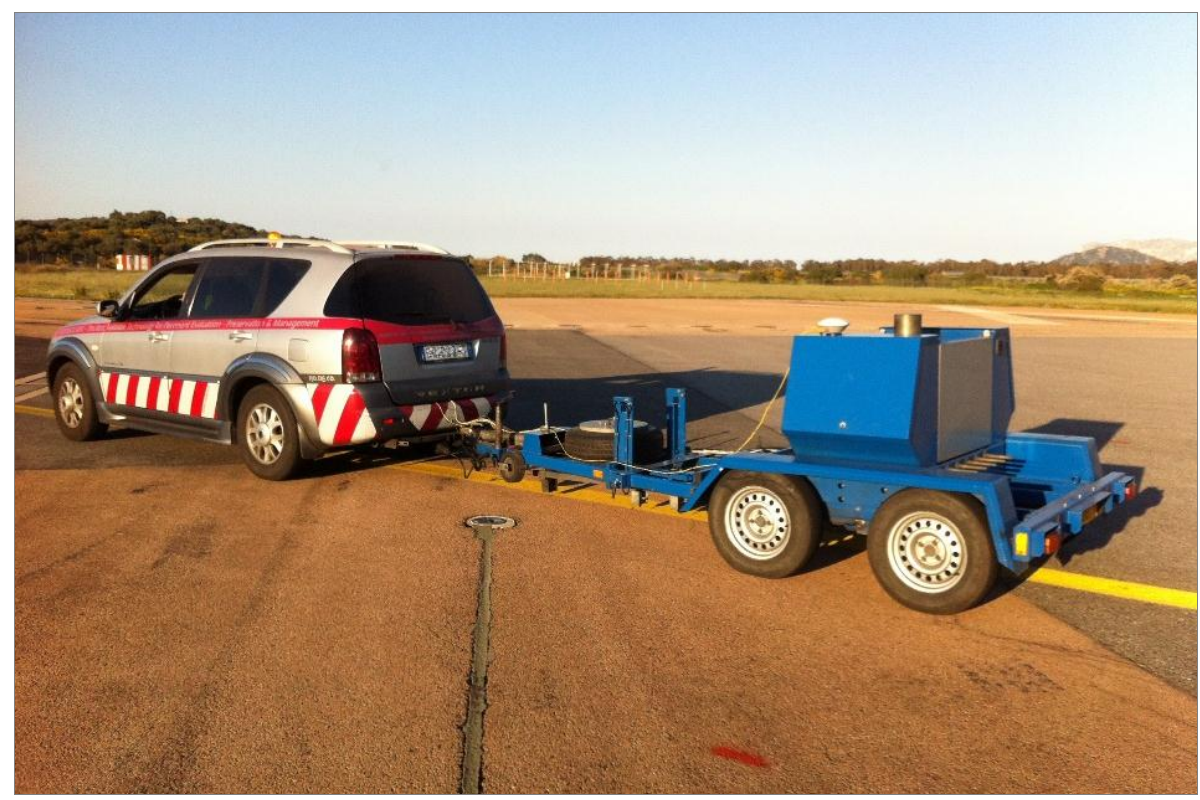

Figure 5. The HWD device

According to the GPR survey inspections the AC layer thickness varies from $240 \mathrm{~mm}$ up to $330 \mathrm{~mm}$. These high thickness variations are related to the maintenance works executed only on fixed sections. On Figure 6 the thickness variation of AC layer is illustrated. 

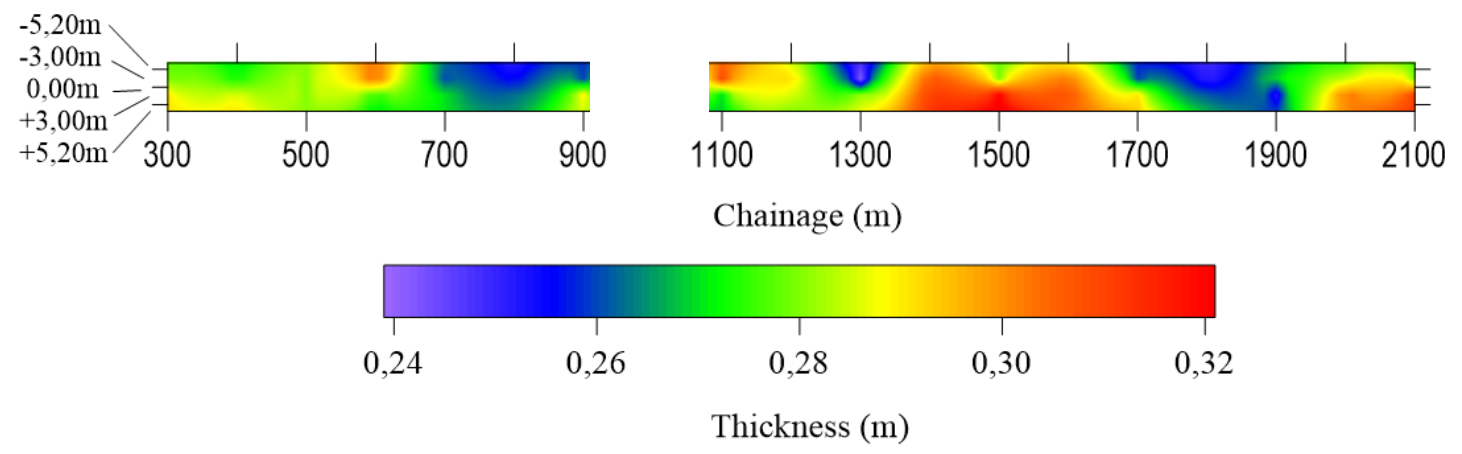

Figure 6. AC layer thickness.

The granular base thickness varies from $340 \mathrm{~mm}$ up to $450 \mathrm{~mm}$ as illustrated on Figure 7.
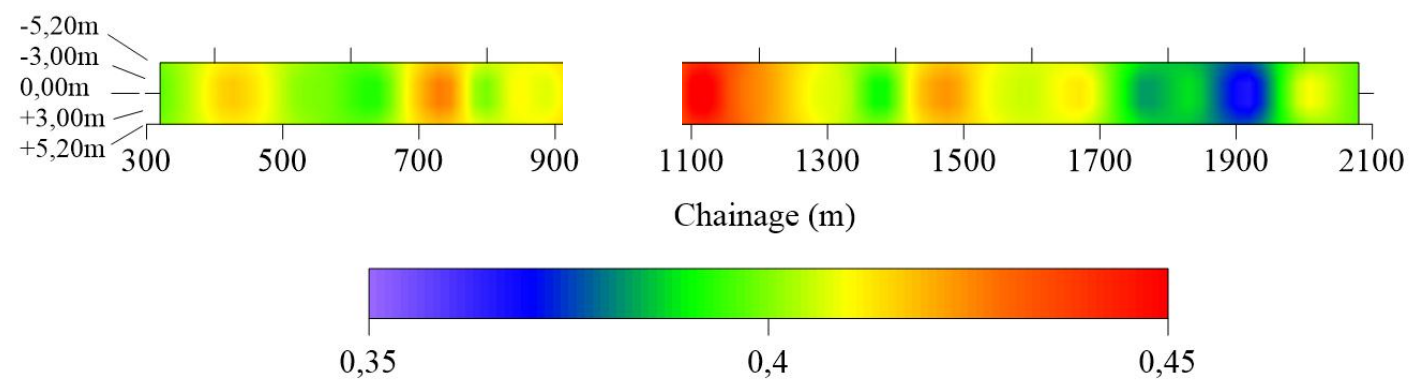

Thickness (m)

Figure 7. Granular Subbase thickness.

A standard runway section is represented on Figure 8.

\begin{tabular}{|c|c|}
\hline \multicolumn{2}{|c|}{ RUNWAY PAVEMENT SECTION } \\
\hline & HMA $-290 \mathrm{~mm}$ \\
\hline & Granular Subbase $-400 \mathrm{~mm}$ \\
\hline & Subgrade \\
\hline
\end{tabular}

Figure 8. Typical inspected runway section.

To establish the number and the spacing between alignments of tests the first step was to analyze the annual traffic of aircraft. Then alignments have been identified on the basis of the prevailing trajectories covered by aircraft, taking into account the recommendations of the ICAO Annex 14, FAA AC 5300-13A and FAA AC 5380-9. The FAA recommends measuring the runway surface along the centerline and at a lateral offset (left and right) that approximates the aircraft using the airport. A 3.05 meter offset can effectively address Airplane Design Group (ADG) II and III aircrafts, 
while a 5.22 meter (17.5 feet) offset can address ADG IV, V, and VI aircrafts. Due to the increase by movements of wide body registered on last years, all offset recommended were chosen. AC paved area were investigated on five alignments corresponding with centerline, $\pm 3,00 \mathrm{~m}$ and $\pm 5,20 \mathrm{~m}$ from the CL with a distance between of $100 \mathrm{~m}$.

Then in July 2013 the runway was investigated with different load input in two test sections respectively, 500 and 900 meters long, shown on Figure 9. In the 500 meters section, 30 points were measured corresponding with the touchdown zone of Threshold 05. The second section, 900 meters running from middle runway up to touchdown zone located at Threshold 23, 50 points were measured.

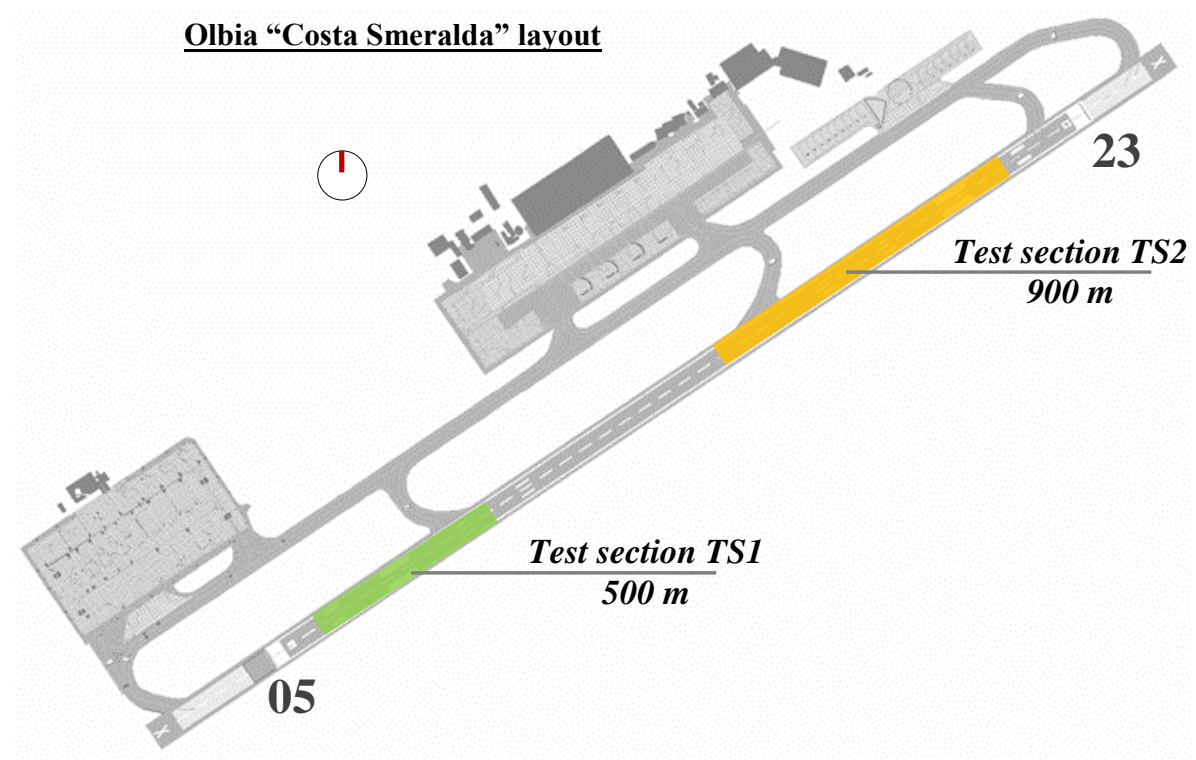

Figure 9. Location of Test sections

Due to the change of season, tests were executed on different climatic conditions. The first part of tests was carried out at the end of the rainy season and with temperatures of the pavement equal to $15^{\circ} \mathrm{C}$, while the second part was carried out in the dry period with an average temperature of the pavement equal to $35^{\circ} \mathrm{C}$.

The tests carried out in April 2013 have shown a strong variability of the peak deflection measured, ranging from a minimum of $842 \mu \mathrm{m}$ up to $1824 \mu \mathrm{m}$.

- The alignment at +5.20 m shows a range of deflection between a minimum of $903 \mu \mathrm{m}$ (progressive $2000 \mathrm{~m}$ - TS2) and a maximum of $1801 \mu \mathrm{m}$ (progressive $1200 \mathrm{~m}-\mathrm{TS} 2$ ). The standard deviation $\sigma$ is 229 , which demonstrates high variability.

- The alignment at +3.00 m shows a range of deflection between a minimum of $930 \mu \mathrm{m}$ (progressive $2000 \mathrm{~m}$ - TS2) and a maximum of $1824 \mu \mathrm{m}$ (progressive $1600 \mathrm{~m}-\mathrm{TS} 2$ ). Also this alignment is characterized by high variability, with a standard deviation $\sigma$ of 224 .

- The alignment on the center line shows a range of deflections between a minimum of $842 \mu \mathrm{m}$ (progressive $1100 \mathrm{~m}$ - TS2) and a maximum of $1296 \mu \mathrm{m}$ (progressive $1500 \mathrm{~m}-\mathrm{TS} 2$ ). The standard deviation $\sigma$ falls to 123 . 
- The deflections of alignment at $-3.00 \mathrm{~m}$ ranges from $973 \mu \mathrm{m}$ (progressive 600 $\mathrm{m}-\mathrm{TS} 1$ ) up to 1416 (progressive $1500 \mathrm{~m}-\mathrm{TS} 2$ ). The standard deviation is 122.

- The deflections of alignment at $-5.20 \mathrm{~m}$ ranges from $910 \mu \mathrm{m}$ (progressive $1200 \mathrm{~m}-\mathrm{TS} 2$ ) up to $1474 \mu \mathrm{m}$ (progressive $1900 \mathrm{~m}$ - TS2). The standard deviation $\sigma$ is 152 .

The analysis of maximum deflections, represented on Figure 10, show that the critical runway portion is located between the progressive 1200 and $1500 \mathrm{~m}$, with a mean value of $1352 \mu \mathrm{m}$ and at progressive $1700 \mathrm{~m}$, with a mean value of $1287 \mu \mathrm{m}$. Lower values on center line alignment can be related at lower stress inducted by aircraft due to the only nose gear coverage.

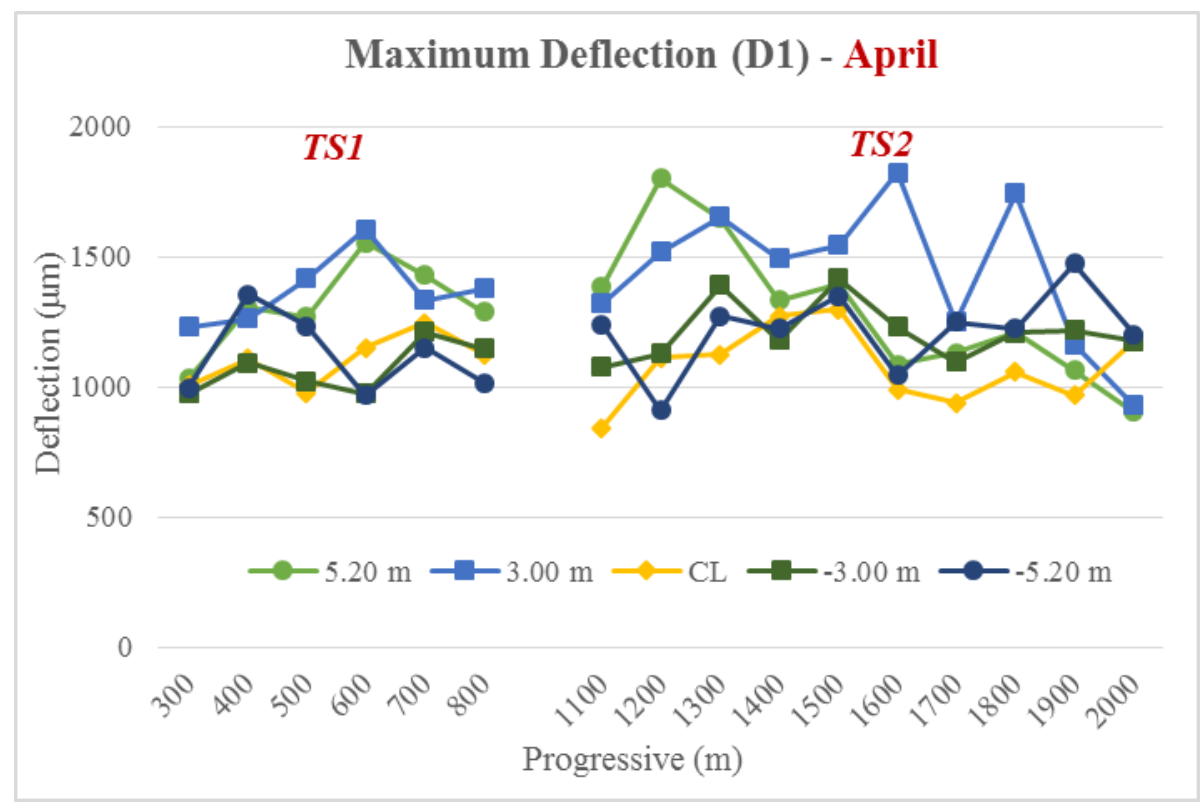

Figure 10. Maximun deflection at center load - April 2013

The tests carried out in July 2013, as mentioned, were executed with different load thus the related deflections were affected by the variability on stress applied. The results are resumed below.

- The alignment at $+5.20 \mathrm{~m}$ shows a range of deflection between a minimum of $525 \mu \mathrm{m}$ (progressive $2000 \mathrm{~m}$ - TS2) and a maximum of $1425 \mu \mathrm{m}$ (progressive $1200 \mathrm{~m}-\mathrm{TS} 2$ ). The standard deviation $\sigma$ is 222 .

- The alignment at $+3.00 \mathrm{~m}$ shows a range of deflection between $549 \mu \mathrm{m}$ (progressive $2000 \mathrm{~m}-\mathrm{TS} 2$ ) and $1244 \mu \mathrm{m}$ (progressive $600 \mathrm{~m}-\mathrm{TS} 1$ ). The standard deviation $\sigma$ is 181 .

- The alignment on the center line shows a range of deflections between a minimum of $763 \mu \mathrm{m}$ (progressive $500 \mathrm{~m}-\mathrm{TS} 1$ ) and a maximum of $1141 \mu \mathrm{m}$ (progressive $1500 \mathrm{~m}-\mathrm{TS} 2$ ). The standard deviation $\sigma$ is 115 .

- The deflections of alignment at $-3.00 \mathrm{~m}$ ranges from $530 \mu \mathrm{m}$ (progressive 600 $\mathrm{m}$ - TS1) up to 543 (progressive $1300 \mathrm{~m}-\mathrm{TS} 2$ ). The standard deviation is 86 .

- The deflections of alignment at $-5.20 \mathrm{~m}$ ranges from $495 \mu \mathrm{m}$ (progressive 600 $\mathrm{m}-\mathrm{TS} 1$ ) up to $864 \mu \mathrm{m}$ (progressive $1900 \mathrm{~m}-\mathrm{TS} 2$ ). The standard deviation $\sigma$ is 101 . 
Due to the different test conditions, results obtained cannot be immediate comparable. In Figure 11 the deflections obtained are represented. To best evaluate and compare results with first test session a normalization method has been developed aiming to allow the comparison between data obtained on different load and weather conditions.

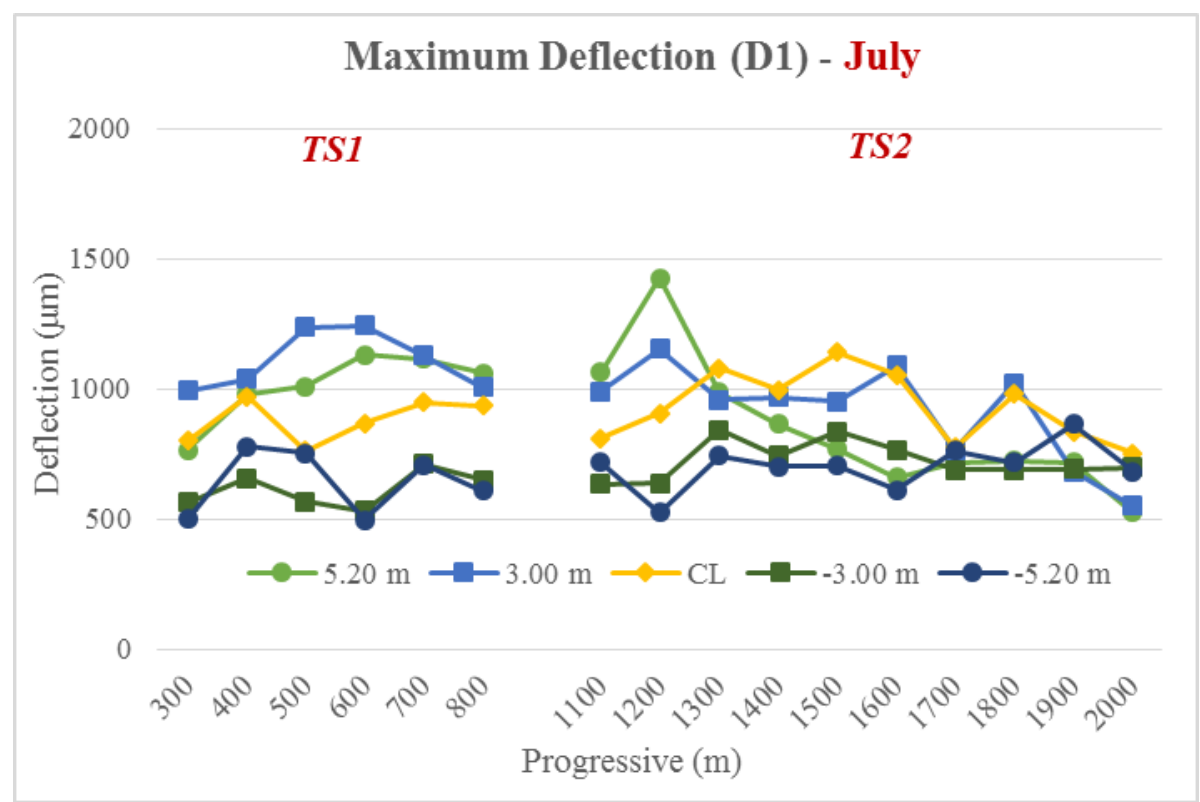

Figure 11. Maximum deflection at center load - July 2013

This method has been used to compare the results of the whole geophones, since these either individually or combined can be used to know about the conditions of pavement inspected.

\section{Data analysis and evaluation}

The comparison of data gathered has been focused on load input and on the relative deflection basin registered by the 9 geophones located, respectively, on the load position (D1) and at 200 (D2) , 300, 450, 600, 900, 1200, 1500 and $1800 \mathrm{~mm}$, as illustrated on Figure 12. 


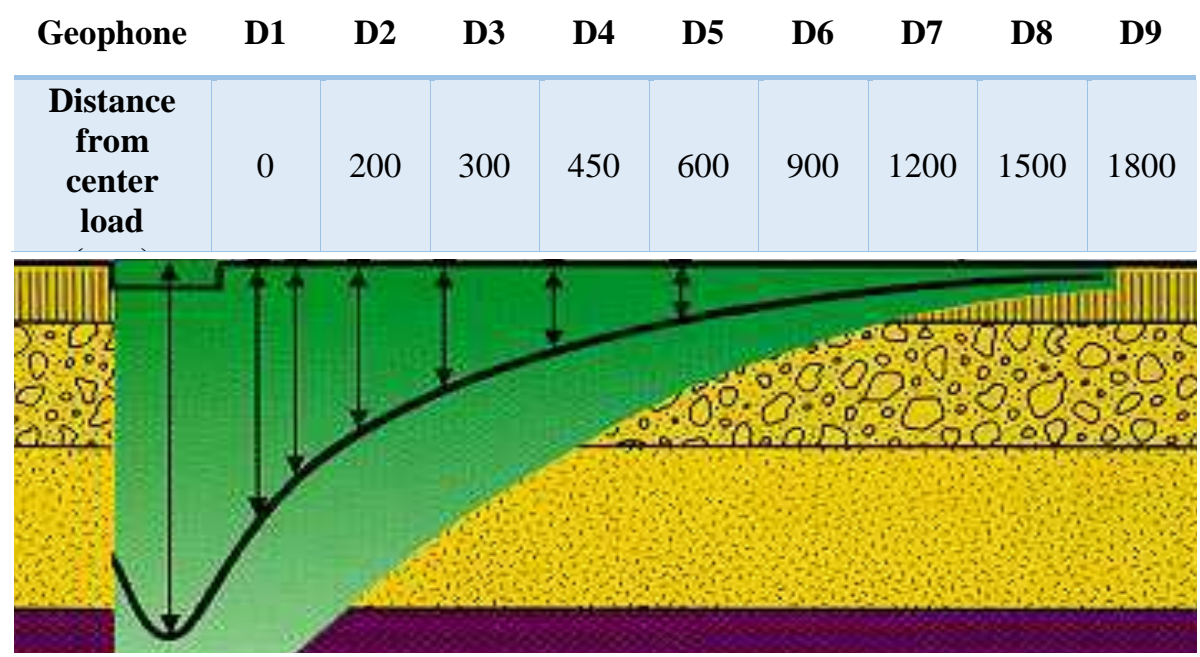

Figure 12. Geophone spacing scheme - standard deflection bowl

The first session of test has been characterized by almost the same load impulse of $145 \mathrm{kN}$ with standard deviation $\sigma$ of 1.1. The second session of test has been executed with four different load impulse: $70(\sigma=0.4), 92(\sigma=0.3), 106(\sigma=0.4)$ and $113(\sigma=$ $0.5)$. The study of measured deflections showed the greater bowls on test conducted in April 2013, due to the greater load impulse. In July 2013, since there were lower loads, deflection were always lower than previous tests.

To make comparable the results obtained from the two test campaigns, two indices of comparison were introduced with the aim at finding a function applying the interpolation method. The first index proposed is the load ratio, defined as the ratio between the load impulse of July 2013 tests and the load impulse of April 2013 tests. Eight different load ratio have been calculated. The load ratio varies between a minimum of 0.48 up to 0.78 . The second index is the deflection ratio, defined as the ratio between the deflection of the $i$ geophone obtained in July 2013 and the deflection of the $i$ geophone obtained in April 2013. Results are shown on Table 1.

Table 1. Load ratio vs Deflection ratio results

\begin{tabular}{|c|c|c|c|c|c|c|c|c|}
\hline $\begin{array}{c}\text { Load ratio index } \\
\text { (July 2013/April 2013) }\end{array}$ & 0.48 & 0.49 & 0.64 & 0.72 & 0.73 & 0.74 & 0.77 & 0.78 \\
\hline \hline \multicolumn{7}{|c|}{ Deflection ratio (July 2013/April 2013) } \\
\hline D1 & 0.58 & 0.60 & 0.76 & 0.84 & 0.81 & 0.82 & 0.85 & 0.82 \\
\hline D2 & 0.55 & 0.57 & 0.73 & 0.79 & 0.77 & 0.79 & 0.82 & 0.82 \\
\hline D3 & 0.53 & 0.55 & 0.70 & 0.76 & 0.76 & 0.78 & 0.80 & 0.80 \\
\hline D4 & 0.52 & 0.52 & 0.69 & 0.72 & 0.74 & 0.76 & 0.79 & 0.79 \\
\hline D5 & 0.50 & 0.49 & 0.67 & 0.69 & 0.73 & 0.75 & 0.78 & 0.76 \\
\hline D6 & 0.45 & 0.45 & 0.67 & 0.65 & 0.72 & 0.75 & 0.74 & 0.71 \\
\hline D7 & 0.43 & 0.45 & 0.68 & 0.64 & 0.72 & 0.77 & 0.74 & 0.72 \\
\hline D8 & 0.40 & 0.41 & 0.65 & 0.66 & 0.69 & 0.72 & 0.70 & 0.74 \\
\hline D9 & 0.39 & 0.41 & 0.64 & 0.68 & 0.67 & 0.69 & 0.70 & 0.66 \\
\hline
\end{tabular}

A good fitting linear interpolation was obtained from proposed indexes. The functions are well correlated, ranging from a minimum of $R^{2}=0.90$ (D7) up to $R^{2}=1.00$ (D3), as shown on Figure 13. 


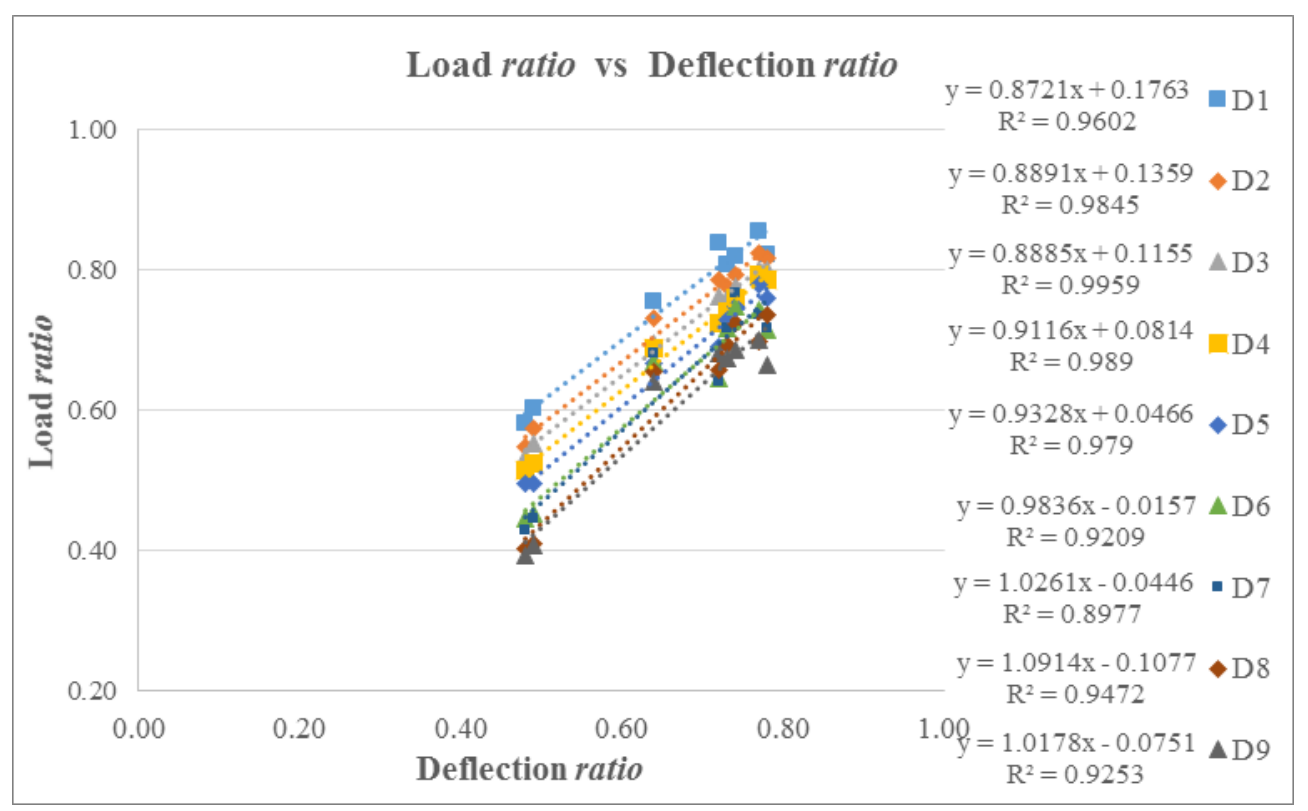

Figure 13. Results of linear interpolation of Deflection ratios

The linear function established for the center load geophone has been applied to rectify the values obtained on test performed in July 2013, and the new representation is shown on Figure 14.

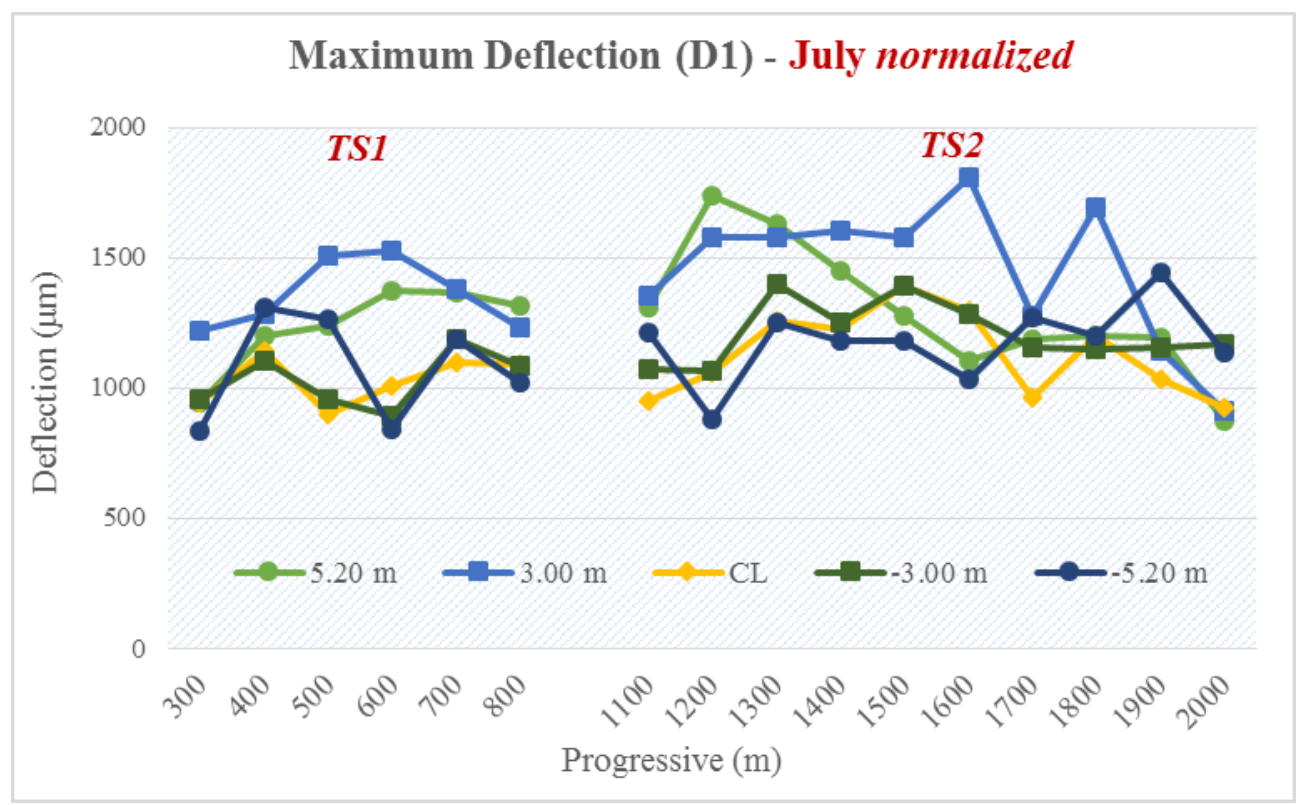

Figure 14. July 2013 maximum deflection after normalization

After the normalization, as expected, the greater corrections were applied for alignments and progressive with lower load ratio index (i.e., 0.48-0.49), especially for the alignments +3.00 and $+5.20 \mathrm{~m}$ between the progressive $1300 \mathrm{~m}$ and $1800 \mathrm{~m}$. The worst conditions were confirmed to be at the alignments +5.20 and +3.00 , especially between $500 \mathrm{~m}$ and $600 \mathrm{~m}$, between $1200 \mathrm{~m}$ and $1600 \mathrm{~m}$ and at progressive $1800 \mathrm{~m}$. Best performance conditions were confirmed at centerline alignment, with an average deflection of $897 \mu \mathrm{m}$. Figure 13 show deflection after normalization. 
Analyzing the results obtained applying the load correction on July 2013 tests, greater deflections of the upper layers then the values measured on April 2013 tests were determined. This effect is due to the lower stiffness of asphalt concrete layers which of course decreases with high summer temperatures. Conversely, the stiffness of the lower unbounded layers was greater on test conducted in July 2013, as expected, since the moisture content was lower than the spring values.

\section{Benchmarking application}

In order to start the development of structural benchmarking parameters for deflection evaluation at network-level, the different tiered condition-rating description, known as RAG system (Red-Amber-Green), has been adopted. Each color is related to the values of deflection measured, respectively severe, warning and sound, corresponding to three levels of structural behavior, that's correspond to weak, poor and good pavement response, as represented on Table 2. According the results of backcalculation process conducted for pavement classification purposes and compared with related deflections, a set of values have been proposed.

Table 2. Benchmark values proposed

\begin{tabular}{|c|c|c|}
\hline Pavement & Structural condition rating & $\begin{array}{c}\text { Deflection parameter (drop } \\
\text { weight } 145 \mathrm{kN})\end{array}$ \\
\hline \multirow{2}{*}{$\begin{array}{c}\text { HMA with } \\
\text { Bituminous Base }\end{array}$} & Sound (Green) & $<1250(\mu \mathrm{m})$ \\
\cline { 2 - 3 } & Warning (Yellow) & $1250-1750(\mu \mathrm{m})$ \\
\cline { 2 - 3 } & Severe (Red) & $>1750(\mu \mathrm{m})$ \\
\hline
\end{tabular}

The application of this technique allow the immediately visual identification of the runway's stiffness as shown on contouring illustrated on Figure 15.

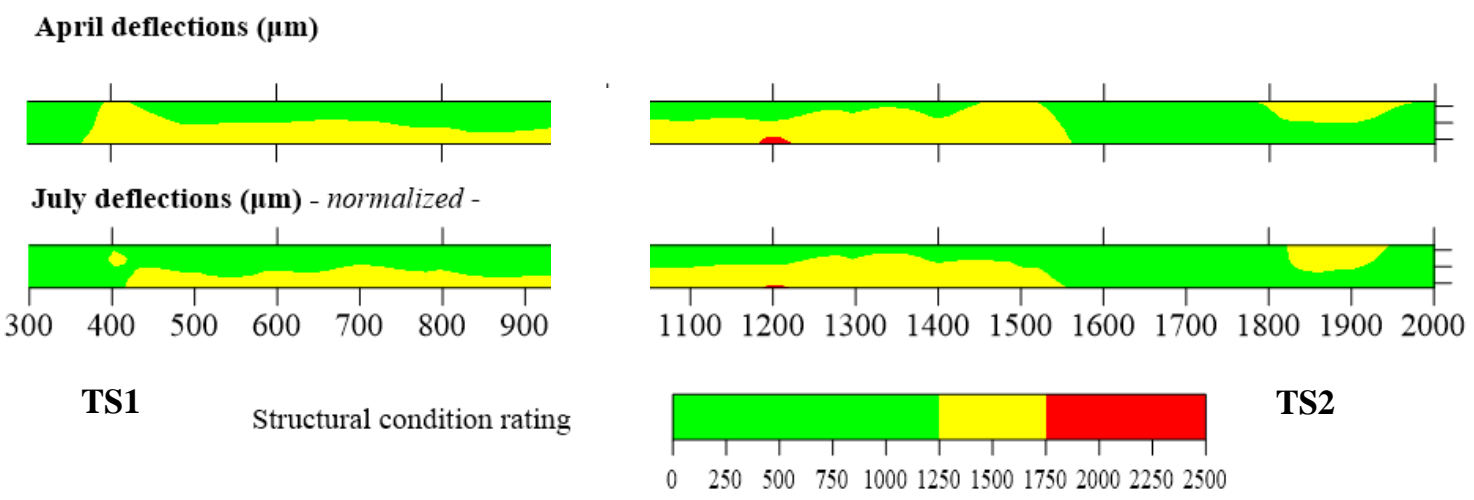

Figure 15. Contouring of benchmark methodology application

\section{Conclusions}

The goal of this work is to set a quickly, easily and standardized method that allow the comparison of deflectometric tests carried out in different conditions and find a set of benchmark parameters for network-level evaluations. As an overall rating of pavement load carrying capacity can be directly obtained by analyzing deflection measured, helping operators to best select the appropriate decisions on pavement 
maintenance without the need of back-calculation process. Tests were conducted with a deflectometer device which is one of the most valuable non-destructive survey equipment for the structural evaluation. Otherwise, the literature review allowed identifying the factors that can affect results, playing a crucial role on correct interpretation of data gathered.

In this paper results obtained from HWD surveys were discussed. Two test sections of the runway of Olbia "Costa Smeralda" airport, respectively length $500 \mathrm{~m}$ and $900 \mathrm{~m}$, were investigated in different climatic conditions and with different load impulse. The Airport stands out for the high seasonality due to the strong increase of aircraft movements on summer season. In this case, airport operators, as the maneuvering area become very busy, have to restrict maintenance work and monitoring programs, as it can induct low profit for management company due to the stop of flights.

Due to the differences on load applied between April 2013 and July 2013 campaigns, the comparison was conducted introducing two indexes, the load ratio and the deflection ratio. The data determined were then investigated and a good linear interpolation, well correlated, was found for each one of geophones fitted.

Tests conducted in April 2013 highlighted that generally weak conditions can be noticed on $+5.20 \mathrm{~m}$ and $+3.00 \mathrm{~m}$ alignments, with worst conditions between $1200 \mathrm{~m}$ to $1600 \mathrm{~m}$ and at progressive $1800 \mathrm{~m}$. These results were also confirmed after normalization of tests carried out on July 2013, which if evaluated without the normalization proposed could lead in misleading conclusions.

Due to the different applied load was not possible to establish a definite reliability of the influence of seasonality changes. However, the results of the tests can be validated by performing additional tests conducted in the same period and applying reversed load intensity. Applying normalization on deflection tests has allowed the use of benchmarking methodology for easy and rapid assessment of pavement conditions at network-level.

In this work the basis for the development of such a relative structural benchmarking have been arranged, also allowing the comparison of test conducted on different conditions. To validate and enhance the method and the benchmark values proposed, more studies are needed. Further studies will focus on possible application of this approach on others parameters for evaluation of structural behavior related to each layer.

\section{Acknowledgements}

The Authors would like to thank the GEASAR S.p.A., the Olbia Airport Management Company, for strongly support investigations conducted.

\section{References}

Briggs, R. C. \& Lukanen, E. O., 2000. Variations in Backcalculated Pavement Layer Moduli in LTPP Seasonal Monitoring Sites. s.1.:ASTM.

Carvalho, R. et al., 2012. Simplified Techniques for Evaluation and Interpretation of Pavement Deflections for Network-Level Analysis. s.1.:s.n. 
COST 336, A., 1998. Information gathering report, s.1.: s.n.

Donovan, P. \& Tutumluer, E., 2009. Use of Falling Weight Deflectometer testing to determine relative damage in asphalt pavement unbound aggregate layers. s.l., s.n.

FAA AC 150/5370-11B, 2011. AC 150/5370-11B - Use of Nondestructive Testing in the Evaluation of Airports Pavements. s.l.:FAA.

Gadafa, D., Hossain, M., Miller, R. \& Van, T., 2010. Estimation of Remaining Service Life of Flexible Pavements from Surface Deflections. Journal of Trasportation Engineering, 136(4), pp. 342-352.

Haas, R., 1995. Principles and Apllications of Pavement Management. Singapore, Second International Conference on Road and Airfield Pavement Technology Vol.1.

Horak, E., 2007. Surface moduli determined with the falling weight deflectometer used as benchmarking tool. Pretoria, ZA, s.n.

Horak, E., 2008. Benchmarking the structural condition of flexible pavements with deflection bowl parameters. Journal of the South African Institution of Civil Engineering, 50(2), pp. 2-9.

Horak, E., 2009. Evaluation of airport pavements with FWD deflection bowl parameter benchmarking methodology. Amsterdam, s.n.

Paine, D., 1998. The incorporation of structural data in a pavement management system. s.1., 4th International Conference on Managing Pavements.

Peddibhotla, S., Murphy, M. \& Zhang, Z., 2011. Validation and Implementation of the Structural Condition Index (SCI) for Network-level Pavement Evaluation, s.1.: s.n.

Shahin, M., 2005. Pavement Management for Airports, Roads, and Parking Lots. s.1.:s.n.

Thompson, M. \& Cation, K., 1986. A Proposed Full-Depth Asphalt Concrete Thickness Design Procedure, s.l.: Civil Engineering Series No. 45, Illinois Cooperative Highway and Transportation Series No. 213.

Ullidtz, P., Zhang, W. \& Baltzer, S., 2000. Validation of Pavement Response and performance models. s.1.:s.n. 